\title{
Effects of Hydropower Reservoir Withdrawal Temperature on Generation and Dissipation of Supersaturated TDG
}

\author{
Lei Tang*, Ran Li *†, Ben R. Hodges**, Jingjie Feng* and Jingying Lu* \\ *State Key Laboratory of Hydraulics and Mountain River Engineering, Sichuan University, 24 south Section 1 Ring \\ Road No.1 ChengDu, SiChuan 610065 P.R.China \\ **Department of Civil, Architectural and Environmental Engineering, University of Texas at Austin, USA \\ $\dagger$ Corresponding author: Ran Li; liran@scu.edu.cn
}

Nat. Env. \& Poll. Tech. Website: www.neptjournal.com

Received: 29-07-2019

Accepted: 08-10-2019

\section{Key Words:}

Hydropower;

Total dissolved gas;

Supersaturation;

Hydropower station

\begin{abstract}
One of the challenges for hydropower dam operation is the occurrence of supersaturated total dissolved gas (TDG) levels that can cause gas bubble disease in downstream fish. Supersaturated TDG is generated when water discharged from a dam entrains air and temporarily encounters higher pressures (e.g. in a plunge pool) where TDG saturation occurs at a higher gas concentration, allowing a greater mass of gas to enter into solution than would otherwise occur at ambient pressures. As the water moves downstream into regions of essentially hydrostatic pressure, the gas concentration of saturation will drop, as a result, the mass of dissolved gas (which may not have substantially changed) will now be at supersaturated conditions. The overall problem arises because the generation of supersaturated TDG at the dam occurs faster than the dissipation of supersaturated TDG in the downstream reach. Because both generation and dissipation of TDG are functions of water temperature, there is an opportunity to affect the TDG process through selective withdrawal structures at a reservoir. Using a combination of field observations, and hydrodynamic modelling, we analysed the dependence of the water temperature difference on TDG generation from different-elevation release structures of highdam reservoirs. By using of the dissipation model coupled with TDG and temperature, the evolution of supersaturated TDG from different withdrawal structures was simulated and compared in a natural river reach. It showed that warmer withdrawals result in reduced generation of TDG and enhanced dissipation of TDG.
\end{abstract}

\section{INTRODUCTION}

Water temperature is an amazing controlling factor that affects water quality and aquatic system in many aspects, such as the activity of microorganisms, the mass transfer of dissolved gas, and the suitability of habitats for aquatic organisms. The increasing number of dam constructions and operations are causing distinct spatial and temporal changes in the water temperature (Deng et al. 2011). Temperature stratification is one of the dominant characteristics of large and deep reservoirs. According to the literature (Deng 2003), the temperature difference between the surface and the bottom layer in a reservoir may reach as high as $17^{\circ} \mathrm{C}$. To reduce the negative effects on aquatic organisms, various mitigation measures, such as stoplog intake and eco-regulation strategies, have been implemented (Deng et al. 2011, Chen et al. 2016). The temperature-related responses have aroused more public concern, among which is the response of supersaturated total dissolved gas (TDG) to temperature changes.

TDG supersaturation (TDGS) is an adverse impact caused by spill discharge from reservoirs, which is widely understood to cause bubble disease and thereby increase fish mortality (Weitkamp et al. 2003, Liang et al. 2013, Xue et al. 2019). Many studies have been performed on the evolution of TDGS and its mitigation strategies (Politano et al. 2012, Urban et al. 2008, Yingzhu et al. 2018). Li et al. (2009) proposed that two processes are involved in the TDGS problem of large dams. The first process is the generation process of TDGS, in which excessive air is dissolved under high pressure. The second consequent process is the dissipation process, in which the supersaturated TDG dissipates from water in the downstream river. Shen (2014) conducted experiments to explore the effect of water temperature on supersaturated TDG dissipation in static and turbulent conditions. Ou (2016) carried out experiments in both a straight flume and a converted flume to study the relationship between the dissipation coefficient and temperature in flowing water. However, before the present work, no investigation has provided insight into the quantitative response of TDGS to the water temperature stratification related to the reservoir operation. Determining the relationship between TDGS and water temperature variation is not only a practical but also a theoretical challenge for improving high dam operations. 
With respect to the two processes of TDGS, both air dissolution and degasification are closely related to the water temperature. Herein, the paper will describe the response of TDG supersaturation to water temperature changes in each process.

\section{RESPONSE OF SUPERSATURATED TDG GENERATION TO TEMPERATURE CHANGES}

The generation extent of TDGS is closely related to the air solubility at a specific pressure and temperature in a plunge pool. Therefore, we first examine the air solubility dependence on temperature and then discuss the effect of water temperature regulation on the generation of supersaturated TDG.

\section{Air Solubility in Terms of Temperature}

It is well understood that the solubility of dissolved gas decreases as the temperature is increased under specific pressure and salinity (Colt 1984). The air solubilities of oxygen, nitrogen, and carbon dioxide, in units of $\mathrm{mg} / \mathrm{L}$, as a function of temperature are presented in Fig. 1. The data indicate that the air solubility varies with the change in temperature. For example, the solubility of oxygen at barometric pressure is $14.6 \mathrm{mg} / \mathrm{L}, 9.1 \mathrm{mg} / \mathrm{L}$, and $6.4 \mathrm{mg} / \mathrm{L}$ at $0^{\circ} \mathrm{C}, 20^{\circ} \mathrm{C}$, and $40^{\circ} \mathrm{C}$, respectively. The total dissolved gas concentration at barometric pressure is $39.6 \mathrm{mg} / \mathrm{L}, 25.1 \mathrm{mg} / \mathrm{L}$, and 18.0 $\mathrm{mg} / \mathrm{L}$ at $0^{\circ} \mathrm{C}, 20^{\circ} \mathrm{C}$, and $40^{\circ} \mathrm{C}$, respectively. The percentage of dissolved gas saturation level is defined as the ratio of the actual gas concentration to its solubility at a specific temperature. The gas concentration (in $\mathrm{mg} / \mathrm{L}$ ) is expected to be different, even if the per cent TDGS level under different water temperature conditions is equal.

\section{Effect of Water Temperature Regulation on the Generation of TDGS}

In engineering practice, discharges from different elevations of a reservoir usually exhibit different temperatures. Herein, we consider two typical reservoirs as examples to analyse the contribution of the water temperature difference to TDG generation.

Pubugou reservoir in Daduhe River: The Pubugou hydropower station is located at the middle of the Daduhe River. The maximum height of the dam is $186 \mathrm{~m}$, and the backwater length is $72 \mathrm{~km}$. The authors conducted field observations on the water temperature and the TDG from 2012 to 2013. Fig. 2 illustrates the distribution of water temperature in the Pubugou reservoir in August. The water temperature is vertically stratified obviously.

The open spillway and the bottom spillway tunnel are the main release structures of the Pubugou hydropower station, for which the crest elevations are $833 \mathrm{~m}$ and $795 \mathrm{~m}$, respectively. According to the observed results of the water temperature in 2012, the temperatures corresponding to the inlet of the open spillway and the bottom spillway tunnel are $21.4^{\circ} \mathrm{C}$ and $17.3^{\circ} \mathrm{C}$, respectively. The temperature difference is approximately $4.1^{\circ} \mathrm{C}$.

A TDG supersaturation level of $127 \%$ was observed during the discharge of the bottom spillway tunnel, with a flow rate of $2195 \mathrm{~m}^{3} / \mathrm{s}$. As the flow rate of $2195 \mathrm{~m}^{3} / \mathrm{s}$ didn't occur during the operation practice of the open spillway, the TDG level under the same discharge rate was failed to obtain. To compare the sole temperature effect on TDGS, it is reasonable to assume that the open spillway exhibits the

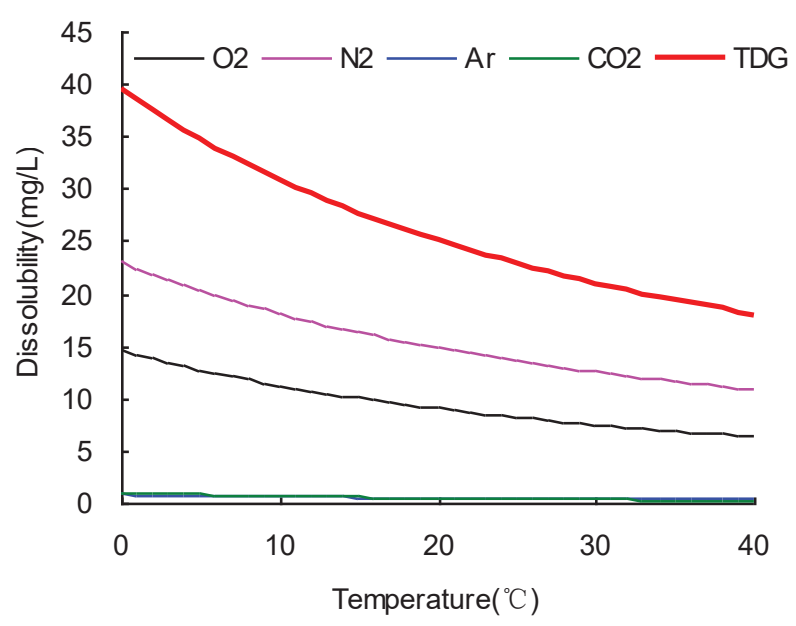

Fig. 1: Solubility of the air compositions and the total dissolved gas versus temperature. 


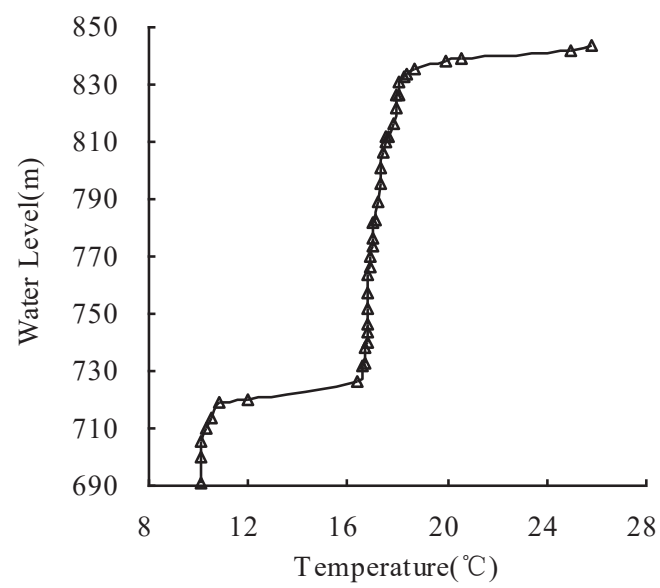

Fig. 2: Observed vertical temperature 1400-m of upstream the dam in the Pubugou Reservoir (Mid-August, 2012).

same TDG level, $127 \%$, with the bottom spillway tunnel. Hence the TDG concentration in $\mathrm{mg} / \mathrm{L}$ can be obtained by multiplying the TDG solubility at the corresponding temperature by the TDG level of $127 \%$. According to Fig. 1, the TDG solubility at $21.4^{\circ} \mathrm{C}$ is $24.4 \mathrm{mg} / \mathrm{L}$ and that at $17.3^{\circ} \mathrm{C}$ is $26.4 \mathrm{mg} / \mathrm{L}$. Thus, the TDG concentrations in $\mathrm{mg} / \mathrm{L}$ of the open spillway and the bottom spillway tunnel are determined to be $31.0 \mathrm{mg} / \mathrm{L}$ and $33.5 \mathrm{mg} / \mathrm{L}$, respectively. The absolute TDG difference is $2.5 \mathrm{mg} / \mathrm{L}$, which is equivalent to $8.1 \%$ of the TDG quantity of the open spillway. The reason for the difference is the TDG solubility difference caused by the temperature difference. According to previous studies, a higher level of TDG generation causes a larger adverse impact on TDG (Li et al. 2013). Therefore, with respect to TDG generation, discharge from the open spillway is more advisable than that from the spillway tunnel.

Baihetan reservoir in Jinshajiang River: The Baihetan hydropower station is a high-dam hydropower station currently under construction on the Jinshajiang River. The maximum height of the dam will be $289 \mathrm{~m}$ and the backwater length

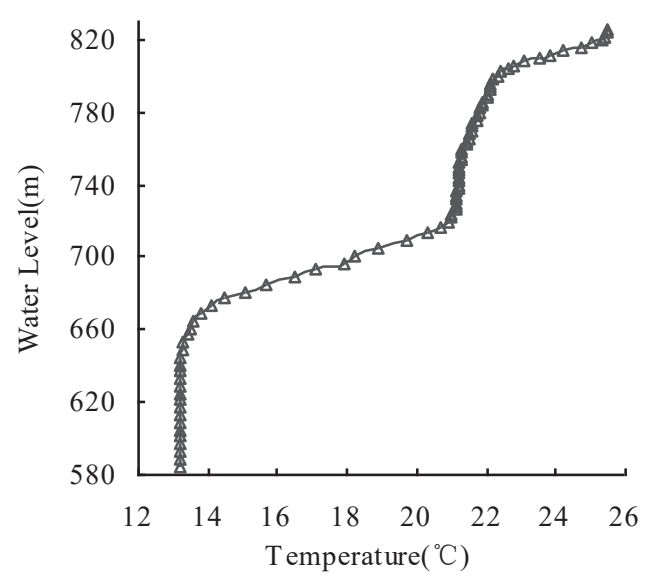

Fig. 3: Predicted vertical temperature upstream of the dam in the Baihetan Reservoir (Mid-September, Dry year).

will be $182 \mathrm{~km}$. Six surface orifices and seven bottom orifices will be included on the on-dam release structures for flood discharge, and the crest elevations will be $810 \mathrm{~m}$ and $714 \mathrm{~m}$, respectively. The predicted temperature distributions in the reservoir for different typical years were obtained by the use of a laterally averaged numerical simulation model (SKLH 2013). Fig. 3 depicts the temperature distribution in the reservoir in September of a dry year. The predicted water temperature corresponding to the depths of the surface orifices and the bottom orifices are $24.8^{\circ} \mathrm{C}$ and $20.8^{\circ} \mathrm{C}$, respectively.

According to Fig. 1, at barometric pressure, the air dissolubility at $24.8^{\circ} \mathrm{C}$ and $20.8^{\circ} \mathrm{C}$ is $22.93 \mathrm{mg} / \mathrm{L}$ and 24.67 $\mathrm{mg} / \mathrm{L}$, respectively. The difference in TDG concentration is $1.74 \mathrm{mg} / \mathrm{L}$, and the relative difference is approximately $7.6 \%$. According to the predicted results of TDG supersaturation caused by the release structures (SKLH 2008), the percentage level of TDG supersaturation at the exit of the plunge pool will be as high as $140 \%$ when the dam discharges. Assuming that the supersaturation value of $140 \%$ is valid for both the surface-orifice discharge and the bottom-orifice discharge,

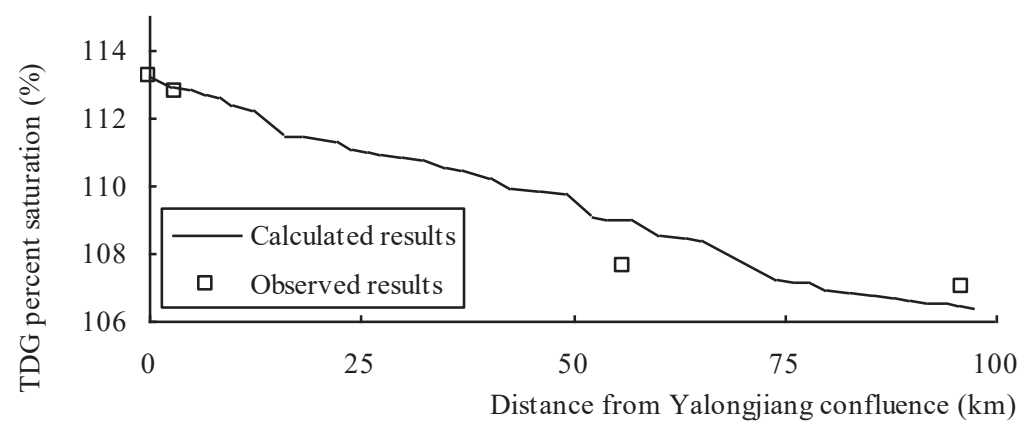

Fig. 4: Comparison of the TDG level between the calculated and observed results in the Jinshajiang River. 
the equivalent TDG contents at $24.8^{\circ} \mathrm{C}$ (surface orifice) and $20.8^{\circ} \mathrm{C}$ (bottom orifice) are $32.10 \mathrm{mg} / \mathrm{L}$ and $34.54 \mathrm{mg} / \mathrm{L}$, respectively. The difference of the TDG concentrations for the surface-orifice discharge and the bottom-orifice discharge is as high as $2.45 \mathrm{mg} / \mathrm{L}$ due to the temperature difference, which is equivalent to $7.6 \%$ of the TDG level at the surface orifice. For this reason, discharge from the surface orifices is more advisable than that from the bottom-orifices.

\section{RESPONSE OF THE SUPERSATURATED TDG DISSIPATION PROCESS TO TEMPERATURE CHANGES}

During the transport of the TDG-supersaturated discharge flow downstream, the water temperature changes as it travels due to the effects of solar radiation and heat transfer with air. In response to the change in water temperature, the gas solubility and the dissipation rate of supersaturated TDG changes, consequently resulting in different dissipation processes of the TDG.

Using the discharge flow from the Baihetan hydropower station as an example, a 1-D model was employed to simulate the dissipation process of TDGS at different temperature conditions.

\section{Prediction Model}

The model couples hydrodynamics, temperature and TDG. The governing equations are as follows:

Continuity equation:

$$
\frac{\partial A}{\partial t}+\frac{\partial Q}{\partial x}=L_{q}
$$

Momentum equation:

$$
\frac{\partial Q}{\partial t}+\frac{\partial}{\partial x}\left(\frac{\alpha Q^{2}}{A}\right)+g A\left(\frac{\partial Z}{\partial x}+S_{f}\right)+L_{q} \frac{Q}{A}=0
$$

Temperature equation:

$$
\frac{\partial(Q T)}{\partial x}=\frac{\partial}{\partial x}\left(A D_{L} \frac{\partial T}{\partial x}\right)+\frac{b \varphi_{n}}{\rho C_{p}}
$$

TDG equation:

$$
\frac{\partial(A C)}{\partial t}+\frac{\partial(Q C)}{\partial x}=\frac{\partial}{\partial x}\left(A D_{L} \frac{\partial C}{\partial x}\right)-K_{T}\left(C-C_{s(T)}\right)
$$

In the above equations, $x=$ the longitudinal distance $(\mathrm{m})$. $t=$ time $\left(\mathrm{s}^{-1}\right) \cdot T=$ Temperature $\left({ }^{\circ} \mathrm{C}\right) \cdot Q=$ the flow rate $\left(\mathrm{m}^{3} / \mathrm{s}\right)$. $A=$ the area of the cross-section $\left(\mathrm{m}^{2}\right) . D_{L}=$ the turbulent diffusivity $\left(\mathrm{m}^{2} / \mathrm{s}\right) \cdot \rho=$ the water density $\left(\mathrm{kg} / \mathrm{m}^{3}\right) \cdot C_{p}=$ the specific heat of water $\left[\mathrm{J} /\left(\mathrm{kg} \cdot{ }^{\circ} \mathrm{C}\right)\right], b=$ the width of the cross-section (m). $\varphi_{n}=$ the heat flux between water and air $\left(\mathrm{W} / \mathrm{m}^{2}\right) . C=$ the TDG concentration in $\mathrm{mg} / \mathrm{L}$. $C_{s(T)}=$ the TDG solubility capacity in $\mathrm{mg} / \mathrm{L}$ with respect to the local temperature $T . K_{T}$ $=$ the first-order transfer rate coefficient with respect to the local temperature $T(1 / \mathrm{s})$.

$\varphi_{n}$ is estimated according to the meteorological data from the weather stations in Qiaojia in the Yunnan province and Huize in the Sichuan province.

In previous studies, degasification was modelled using first-order kinetics for the TDG concentration (USACE 2005). Liu (2013) conducted a series of TDG dissipation experiments at different water temperatures and developed the relationship of the TDG dissipation coefficient versus water temperature that is described as follows:

$$
K_{T}=K_{20} \times 1.062^{(T-20)}
$$

Where, $K_{20}$ in equation (5) can be determined by the observed values analogically or can be determined according to the following equation derived by Feng et al. (2014):

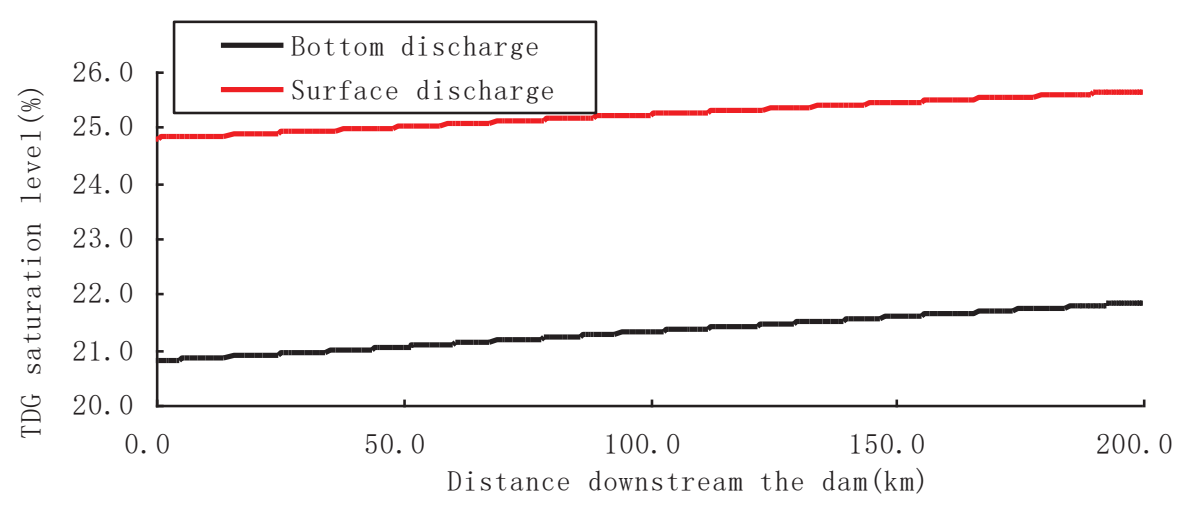

Fig. 5: Evolution of the temperature in the Jinshajiang River downstream of the Baihetan Dam. 


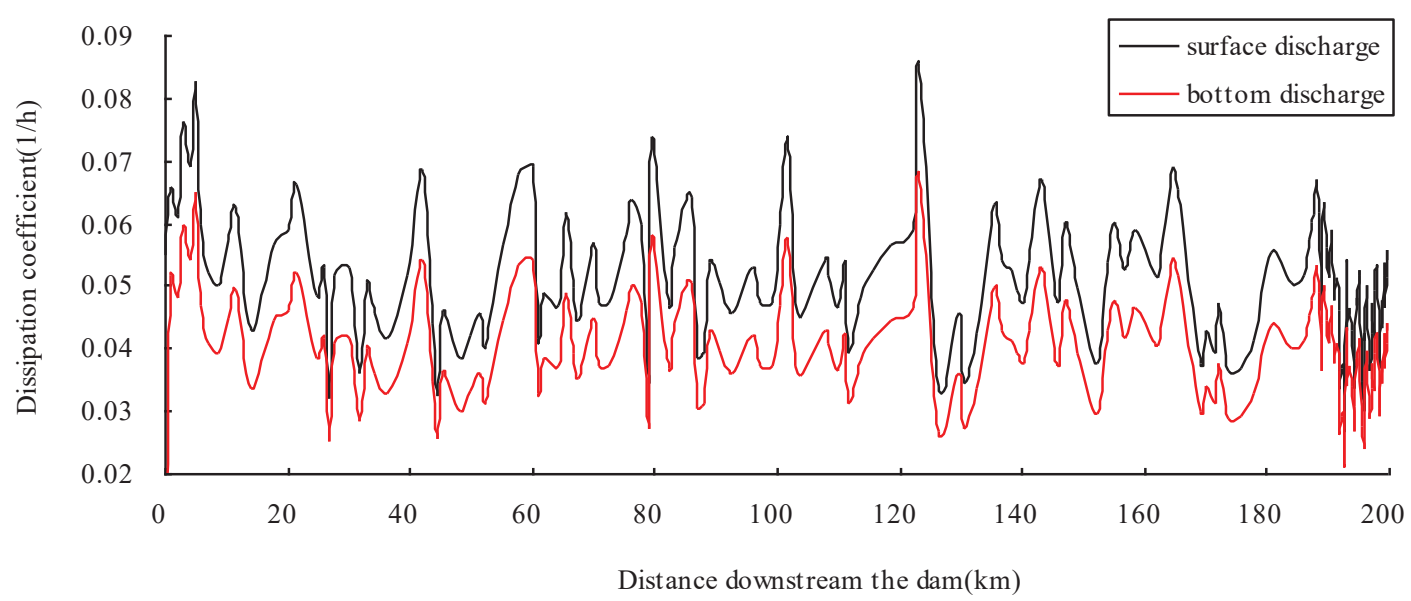

Fig. 6: TDG dissipation coefficient of the Jinshajiang River downstream of the Baihetan Dam.

$$
K_{20}=3600 \phi \frac{u_{*}}{R}\left(\frac{H}{R}\right)^{2.02} F r^{1.73}
$$

According to equation (5), the TDG dissipation coefficient will increase to 1.4 times the original value when the water temperature rises $5^{\circ} \mathrm{C}$ and 1.8 times the original value when the water temperature rises $10^{\circ} \mathrm{C}$, resulting in very different dissipation states of the supersaturated TDG.

\section{Model Verification}

A field observation on the dissipation of supersaturated TDG was conducted by Sichuan University on the river reach from the confluence of the Yalongjiang River and the Jinshajiang River to Longjie ferry. The observed reach is approximately $100 \mathrm{~km}$. The observed results were used to verify the model as depicted in Fig. 4.

\section{Case Description}

Using the discharge of the Baihetan hydropower station as an example, the morphological data were employed to simulate the dissipation process of TDGS at different temperature conditions. The simulation cases and the boundary conditions are listed in Table 1.

\section{RESULTS AND DISCUSSIONS}

Fig. 5 shows that the water temperature increases slowly along the river reach. The temperature increment within $200 \mathrm{~km}$ is $0.8^{\circ} \mathrm{C}$ for the bottom discharge and $0.97^{\circ} \mathrm{C}$ for the surface discharge. The temperature increase along the river reach is very small due to the large flow rate and the high water depth. This result indicates that the impact of the temperature difference from different release structures continues for a very long distance from the dam.

As a function of velocity and water depth, the TDG dissipation coefficient of the Jinshajiang River downstream of the Baihetan Dam was calculated according to equation (6), as derived by Feng et al. (2014), and the results are shown in Fig. 6. The coefficient values fluctuate in the range of 0.03 $\mathrm{h}^{-1} \sim 0.09 \mathrm{~h}^{-1}$ for the surface discharge and $0.02 \mathrm{~h}^{-1} \sim 0.07 \mathrm{~h}^{-1}$ for the bottom discharge. The maximum difference of the coefficients of the two discharges is $0.018 \mathrm{~h}^{-1}$ at the section $123-\mathrm{km}$ downstream of the dam.

The evolution of the TDG per cent saturation level for each discharge case is presented in Fig. 7. The dissipation process of TDG from the surface discharge is significantly faster than that of the bottom discharge. The percentage of the TDG saturation level of the surface discharge decreases

Table 1: Simulation cases and boundary conditions of the Baihetan hydropower station.

\begin{tabular}{|lllll|}
\hline Case No. & Discharge Structure & Discharge temperature $\left({ }^{\circ} \mathrm{C}\right)$ & TDG level in per cent $(\%)$ & TDG level $(\mathrm{mg} / \mathrm{L})$ \\
\hline 1 & Surface orifice & 24.8 & 140 & 32.10 \\
2 & Bottom orifice & 20.8 & 140 & 34.54 \\
\hline
\end{tabular}




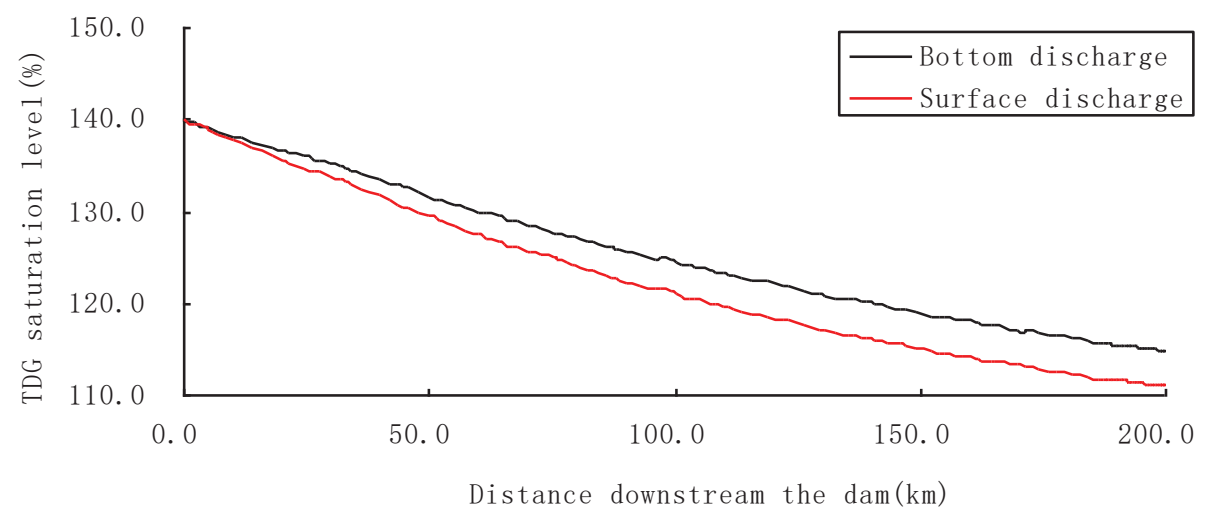

Fig. 7: Evolution of the TDG saturation level in the Jinshajiang River downstream of the Baihetan Dam.

$27.9 \%$ within $200 \mathrm{~km}$, whereas that of the bottom discharge decreases $24.0 \%$ within $200 \mathrm{~km}$. The maximum difference of the TDG level at $200-\mathrm{km}$ downstream of the dam is $3.9 \%$, which is equivalent to $16 \%$ of the TDG dissipation of the bottom discharge.

The water temperature is a governing factor in both TDG generation and dissipation. Spills from different elevations result in different generation and dissipation processes of TDG. With respect to TDGS, the use of release structures at the surface is recommended to discharge floods due to the higher temperature near the surface of the reservoir. This result demonstrates that TDGS can be mitigated further by exploring temperature-based operational regulations.

\section{CONCLUSIONS}

The development of hydropower stations and reservoirs causes distinct spatial and temporal changes in water temperature. For high dam hydropower stations, the release structures are designed to be at different elevations. Due to the temperature stratification for large and deep reservoirs, the spill from different release structures may exhibit different water temperatures. This temperature difference can not only result in different TDG generation levels but can also affect the dissipation rate and per cent saturation level in terms of dissolubility.

According to the temperature stratification results of the Pubugou and Baihetan reservoirs, the water temperature difference from different release structures was approximately $4^{\circ} \mathrm{C}$. The relative difference of the TDG generation from the different release structures of the Pubugou and Baihetan reservoirs was analysed to be approximately $7.6 \%$ and $8.1 \%$, respectively, due to the temperature difference.

By using the discharge of the Baihetan high dam as an example, the dissipation processes of supersaturated TDG from different release structures at different water temperatures were simulated employing a proposed numerical model. Two different dissipation processes of TDG were obtained. The difference of the TDG per cent saturation levels at 200$\mathrm{km}$ downstream of the dam is $3.9 \%$, which is equivalent to $16 \%$ of the TDG decrement of the bottom discharge. This result demonstrates that water temperature plays an important role in the TDG dissolubility, both in the dissipation rate and the per cent saturation level. The response of TDG to water temperature changes implies that water temperature changes should be taken into account in the study of the TDG supersaturation problem of high dam discharges.

Discharges from different elevations exhibit different TDG generation and dissipation processes. With respect to TDG supersaturation, the use of release structures at higher elevations is recommended for discharge due to the elevated temperature near the surface of the reservoir. This recommendation implies that the temperature-based operational regulation is an effective approach to minimize the effect of TDG supersaturation.

\section{ACKNOWLEDGEMENTS}

The research was supported by the National Key R\&D Program of China (Grant No. 2016YFC0401710) and the Open Fund of the State Key Laboratory of Hydraulics and Mountain River Engineering, Sichuan University (SKHL1702).

\section{REFERENCES}

Chen, D., Chen, Q., Leon, A. S. and Li, R. 2016. A genetic algorithm parallel strategy for optimizing the operation of reservoir with multiple eco-environmental objectives. Water Resources Management, 30(7): 2127-2142.

Colt, J. 1984. Computation of dissolved gas concentration in water as a function a temperature, salinity and pressure. American Fisheries Society Special Publication, No 14. Bethesda, USA. 
Deng, Y. 2003. Study on the Water Temperature Prediction Model for the Huge and Deep Reservoir (in Chinese). PhD Thesis of Sichuan University. Chengdu.

Deng, Y., Tuo, Y., Li, J., Li, K. and Li, R. 2011. Spatial-temporal effects of temperature control device of stoplog intake for Jinping I hydropower station. Science China Technological Sciences, 54(1): 83-88.

Feng, J.J., Li, R. and Ma, Q. 2014. Experimental and field study on dissipation coefficient of supersaturated total dissolved gas. Journal of Central South University, 21(5): 1995-2003.

Li, R., Hodges, B.R., Yong, X.D. and Feng, J.J. 2013. Comparison of supersaturated total dissolved gas dissipation with dissolved oxygen dissipation and reaeration. Journal of Environmental Engineering, ASCE, 139(3): 385-390

Li, R., Li, J., Li, K. F., Deng, Y. and Feng, J.J. 2009. Prediction for supersaturated total dissolved gas in high-dam hydropower projects. Science in China, 52(12): 3661-3667.

Liang, R.F., Li, B., Li, K.F. and Tuo, Y.C. 2013. Effect of total dissolved gas supersaturated water on early life of David's schizothoracin (Schizothorax davidi). Journal of Zhejiang University-Science B (Biomedicine \& Biotechnology), 14(7): 632-639.

Liu, S.Y. 2013. Temperature Impact on Supersaturated Total Dissolved Gas Generation and Dissipation (in Chinese). Master Thesis of Sichuan University. Chengdu:

Ou, Y. M., Li, R., Hodges, B. R., Feng, J. J. and Pu, C.X. 2016. Impact of temperature on the dissipation process of supersaturated total dissolved gas in flowing water. Fresenius Environ. Bull., 25: 1927-1934.

Politano, M., Amado, A. A., Bickford, S., Murauskas, J. and Hay, D. 2012. Evaluation of operational strategies to minimize gas supersaturation downstream of a dam. Computers and Fluids, 68: 168-185.

Shen, X., Liu, S.Y., Li, R. and Ou Y.M. 2014. Experimental study on the impact of temperature on the dissipation process of supersaturated total dissolved gas. Journal of Environmental Science, 26(9): 1874-1878.

State Key Laboratory of Hydraulics and Mountain River Engineering (SKLH) 2008. Evaluation of the Total Dissolver Gas Supersaturation Impact of Baihetan Hydropower Station on Jinshajiang River. Chengdu, China.

State Key Laboratory of Hydraulics and Mountain River Engineering (SKLH) 2013. Evaluation of the Water Environmental Impact of Baihetan Hydropower Station on Jinshajiang River. Chengdu, China.

Urban, A.L., Gulliver, J.S. and Johnson, D.W., 2008. Modeling total dissolved gas concentration downstream of spillways. Journal of Hydraulic Engineering, 134(5): 550-561.

US Army Corps of Engineers (USACE) 2005. Technical analysis of TDG processes. US Army Corps of Engineers -Northwest Division, Environmental Resources and Fish Planning offices.

Weitkamp, D.E., Sullivan, R.D., Swant, T. and DosSantos, J. 2003. Gas bubble disease in resident fish of the lower Clark Fork River. Transactions of the American Fisheries Society, 132(5): 865-876.

Xue, S., Wang, Y., Liang, R., Li, K. and Li, R. 2019. Effects of total dissolved gas supersaturation in fish of different sizes and species. International Journal of Environmental Research and Public Health, 16.(13): 2444.

Yingzhu, M., Hang, W., Jingjie, F. and Ran, L. 2018. Using the characteristics of river confluence to reduce the negative impact of supersaturated total dissolved gas (TDG). Nature Environment and Pollution Technology, 17(3): 845-852. 